\title{
Comparing Maximum Stresses and Displacements in A Lower Complete Denture with Different Occlusal Plane Levels and Schemes . A Three Dimensional Finite Element Stress Analysis Study
}

\author{
Abdalbasit Ahmed Fatiallah \\ B.D.S M.Sc., Ph.D \\ Assistant Professor college of dentistry University of Baghdad Iraq \\ Suza A. Faraj \\ B.D.S M.Med.Sci \\ Professor college of dentistry University of Baghdad Iraq
}

\begin{abstract}
Purpose of study: A three dimensional stress analysis method was used to assessed the stress distribution and displacement in a lower complete denture

Materials and Methods: The sample consists of three groups, First group :three set of lower complete denture constructed using cast poured from ready made teaching mould to study the effects of balanced, lingualized and monoplane occlusal schemes on the stress distribution when the occlusal plane leveled with upper, middle and lower third of the retro molar pad .the load used in this study was 58.8 Newton directed axially downward applied on specific sites differ with different occlusal schemes.

Results: Both balanced and lingualized occlusal schemes exert minimal stresses and rotational movements around ridge crest when leveled with middle third of retro molar pad while occlusal plane leveled with the lower third of retro molar pad shows more incidence for rotational movements

Conclusion: Stability improved in monoplane occlusal plane over the three occlusal plane levels the posterior of teeth should be adjusted over the ridge crest so that the lateral stresses reduced and increased denture stability.
\end{abstract}

KEYWORD:

Occlusal plane ,lower denture and finite element stress analysis.

$$
\text { محصلة الاجهادات و الازاحات الناتجة في الطقم السفلي الكامل لعدة مفاهيم و مستويات للاطباق دراسة }
$$

طريقة العناصر المحددة ذات الثلاثة أبعاد

$$
\text { النمستخلص واحدة من أصعب المقاييس التجريبية هي محاولة توزيع القوة على النسيج الساند للطقم بشكل كامل. }
$$

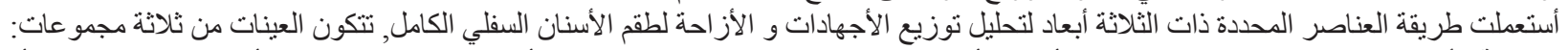

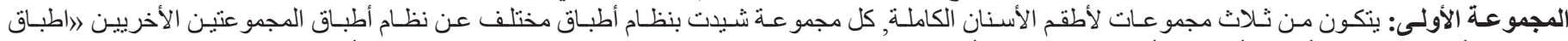

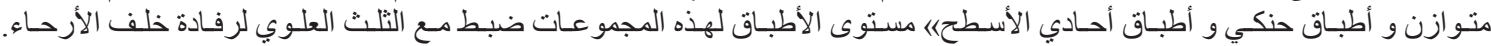

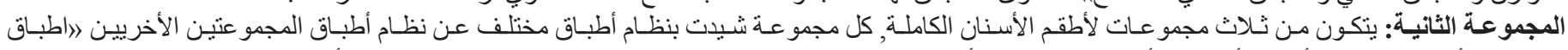

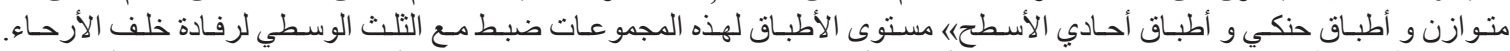

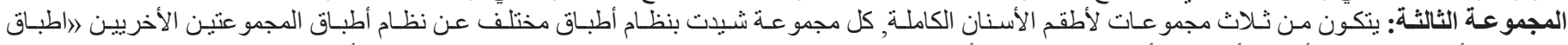

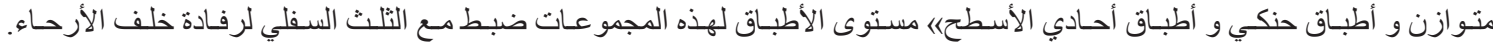

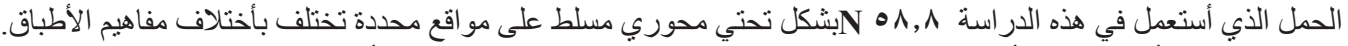

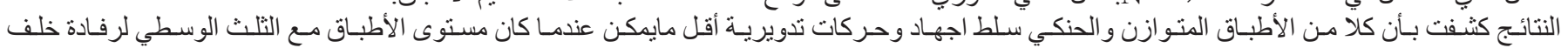

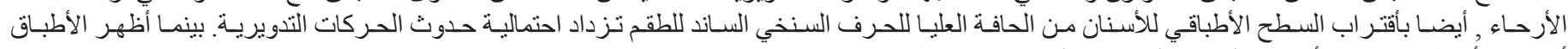

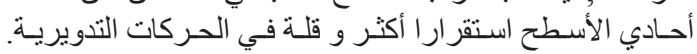

\section{INTRODUCTION:}

Conflict thought concerning the relative merits of occlusal scheme and the debated problems whether the anatomic or non anatomic posterior teeth are more desirable used for constructing complete denture, so to resolve these controversy stresses and denture base deformation reaching the residual ridge determined utilizing a method more concerning with geometrical concept superimposed by physiological requirement to restore and maintain oral health.
Verifying complete denture occlusion intra orally is difficult and unreliable because of the resiliency of the supporting tissue and temporomandibular joint and also because of defective tooth contact so that remounting the denture on an articulator and equilibrating it is an accepted method, then a simulated model transferred to computer in which the analysis carried out. ${ }^{(I)}$

There has been a great deal of interest in the force distribution and base deformation of complete 
denture with various tooth forms during function. ${ }^{(2)}$

The distance between occlusal plane and alveolar crest has an influence on the stability of lower complete denture; the precise location of the occlusal plane is rather a controversial issue. ${ }^{(3)}$

\section{MATERIALS AND METHOD}

The sample grouped so that three sets of complete denture constructed using cast poured from ready made teaching mould Colombia dentoform corporation U.S.A to study the effect of balanced, lingualized and monoplane occlusal schemes on the stress distribution and displacements when the occlusal plane leveled with upper, middle and lower third "(4), (5)"

The imaginary occlusal plane of occlusal rim corresponding to the horizontal plane and the relation of the edentulous arch is class I, then the articulator set so that the sagital and condylar guidance at 30 and 15 degree respectively, and with sagital and condylar inclination at 10 and 0 degree respectively. ${ }^{(6)}$

The lower posterior teeth were first arranged in the three concept of occlusion with the reliable landmarks considered to orient the occlusal plane and position the teeth which is the retro molar pad.

After curing, a section made in each denture at the first molar region mesially and distally to obtain a Bloch section by means of laboratory hand piece and engine ( Q.D. England) with $0.6 \mathrm{~mm}$ disk bur. To facilitate the modeling process and the data input to the programm used (ANSYS 5.4 program version "Swenson analysis system, Houston ,Pennsylvania) the following steps were applied;

1.The mesial and distal area of the denture base were drawn on a grid paper with its exact dimensions through super imposition of them on the grid paper, $\mathrm{x}$ and $\mathrm{y}$ coordinate system obtained for a specific key points to both mesial and distal areas of the denture base.

2.The distance between the mesial and distal area of the denture base block section obtained by the means of Vernier which represent the Z-value in space that change the model from two dimensional to three dimensional model.

3.The mesial and distal areas joined at their key points by lines then the lines converted to areas and the areas converted to volumes which represent the denture base.

4.Modeling of the tooth made by the aid of Vernier through obtaining the real dimension with the selection of a specific key points.

5.the mucosal thickness under the denture supposed to be $1.5 \mathrm{~mm}{ }^{(7)}$
6.The model "tooth, denture base and mucosa" glued together in order to act as one unit through ANSYS options when applying the boundary conditions.

7.Materials properties used in the study mentioned in Table 1.

Boundary condition include the following:

Displacements and load application. For displacements the surface of the mucosa that cover the residual ridge its nodes considered to be fixed in all degree of freedom while load application done according to the site of contacts with the opposing artificial upper teeth in centric

\section{RESULTS}

A load of 58.8 Newton applied and Von mices stresses obtained at specific selected nodes located at the crest of the ridge, middle of the buccal flange and the middle of the lingual flange. ${ }^{(10)}$ Fig. 1

When Comparing maximum stresses among occlusal plane levels in each occlusal scheme a highly significant difference shown among Balanced occlusal scheme leveled with upper third, lower third and middle third of retro molar pad "B1,B2 and B3 Respectively' with the lowest value in B2 and the highest value in $\mathrm{B}$.for lingualized occlusal schemes a similar results obtained. as shown in Table 2 . In case of monoplane occlusal scheme there is no significant different among the three occlusal plane levels in the three sites of measurements

Comparing maximum stresses among occlusal scheme within each level revealed that a highly significant difference among occlusal schemes when occlusal plane leveled with the upper third of retro molar pad with the highest stress value in M1 and the lowest stress value in L1 similar results for the occlusal plane leveled with the middle third of retro molar pad obtained. While for occlusal plane leveled with lower third of retro molar pad also highly significant appeared among them with the highest stress value at B3and the lowest one at L3. Table 2 DISCUSION

When comparing the value of stresses in $\mathrm{B} 1, \mathrm{~B} 2$ and B3, B2 transmits minimal vertical and lateral stresses to the underlying mucosa and similar results with lingualized occlusal scheme this is may be due to the distance between the occlusal surface and ridge crest, the denture base thickness also reduced result in more stresses generated within it. Fig 2,3

While monoplane occlusal scheme posses no statistical difference among the three levels of occlusal plane this is may be due to the fact that the load distributed over a wide area of occlusal surface results in even distribution of stresses through out the 
denture base. Fig 4

When comparing the three occlusal schemes, there were highly significant differences in the stress values at some measurement points on the supporting structure at mucosal-denture base interface in centric occlusion, this is may be due to the buccolingual position of mandibular denture teeth and the point of occlusal load application were differ and this is in agreement with Ohguri et al (7) who conducted a study to show the influence of occlusal schemes on the pressure distribution under a complete denture by comparing fully balanced and lingualized occlusion using pressure transducer attached to simulated dentures.

The monoplane occlusion in all levels considered to transmits the highest stress values to the underlying mucosa than the other occlusal schemes this is in agreement with Kelsey et al ${ }^{(11)}$ who found that greater pressure values obtained with flat zero degree teeth than other type of occlusion "anatomic teeth".

Lingualized occlusion on the other hand transmits minimal occlusal load than the other occlusal schemes due to the fact that the number of occlusal contacts are reduced considerably in that only the palatal cusps of the posterior teeth made contacts in centric relation with the central fossa of the lower posteriors, while the buccal cusps are out of contact. Therefore there is only one centric stopper between upper and lower antagonist posterior teeth.

When occlusal plane leveled with middle third of retro molar pad minimal resultant displacements take place in balanced and lingualized occlusion through out the denture base with no rotational movements occurs, this is because the direction of occlusal force more vertical than lateral force causing the denture base to displace vertically. Fig. 5

As the balanced occlusion leveled with the upper third of retro molar pad, it posses minimal rotational movements around the ridge crest in buccal direction associated with vertical one. On the other hand lingualized occlusal schemes when compared with balanced occlusal scheme performed a more stable movements because it displaced in vertical and slightly lingual direction. Fig 6

In Fig 7 monoplane occlusal scheme results in less trauma to the underlying mucosa because it displaced only in vertical direction.

When occlusal plane leveled with the upper third of RMP the displacement in balanced occlusion was significantly higher than the displacement in both monoplane occlusion and lingualized occlusion, this is in agreement with Stromberg ${ }^{(12)}$ in which he found that by eliminating cusps and using non anatomic teeth we are going to reduce the lateral displacements against the supporting tissue and with Kydd (2) who found that 33 degree posterior teeth produce greater denture base deformation nearly $50 \%$ more than non anatomic flat teeth

While the resultant displacements in monoplane occlusal scheme, when leveled with the middle third of retro molar pad is significantly higher than both balanced and lingualized occlusal scheme with more vertical displacement taking place this is in disagreements with ${ }^{(2)},{ }^{(13)}$

\section{CONCLUSION}

1.Lingualized occlusion transmits minimal stresses to the underlying mucosa at all levels when compared with balanced and monoplane occlusion.

2.In balanced and lingualized occlusal schemes, when reducing the occlusal plane surface of teeth more incidences of rotational movements will occur.

3.In monoplane occlusal scheme stability improved over the three occlusal plane levels and does not exert rotational movements around the ridge crest.

4.Posterior teeth should be adjusted over the ridge crest so that the lateral displacements and stresses reduced and increase denture stability.

Table 1 shows materials properties used in the finite elements study

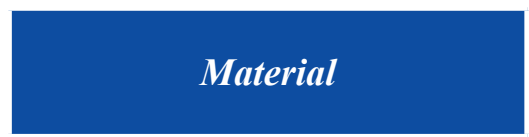

Young modulus "GPa"
Poison's Ratio

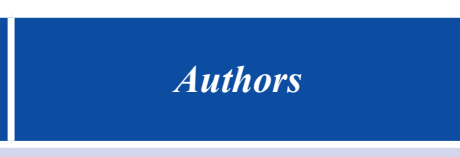
0.35
Craig ${ }^{(8)}$
Tooth
2.65

0.35

Craig ( ${ }^{(8)}$

Acrylic resin denture base

2.65

0.45

Larabee and Glate ${ }^{(9)}$ 
Table 2 Stress values in (MPa) At the mucosa-denture base interface in centric occlusion.

\begin{tabular}{|c|c|c|c|c|c|c|c|c|c|}
\hline & \multicolumn{3}{|c|}{ Balanced occlusal concept } & \multicolumn{3}{|c|}{ Lingualized occlusal concept } & \multicolumn{3}{|c|}{ Monoplane occlusal concept } \\
\hline & $\begin{array}{l}\text { Level of } \\
\text { Occlusal } \\
\text { plane }\end{array}$ & $\begin{array}{c}\text { Mean } \\
\text { stresses } \\
(M P a)\end{array}$ & $\begin{array}{c}\text { St.D Of } \\
\text { Mean }\end{array}$ & $\begin{array}{l}\text { Level of } \\
\text { Occlusal } \\
\text { plane }\end{array}$ & $\begin{array}{c}\text { Mean } \\
\text { stresses } \\
(M P a)\end{array}$ & $\begin{array}{c}\text { St.D Of } \\
\text { Mean }\end{array}$ & $\begin{array}{c}\text { Level of } \\
\text { Occlusal } \\
\text { plane }\end{array}$ & $\begin{array}{c}\text { Mean } \\
\text { stresses } \\
(M P a)\end{array}$ & $\begin{array}{c}\text { St.D of } \\
\text { Mean }\end{array}$ \\
\hline \multirow{3}{*}{$\begin{array}{l}\text { Crest } \\
\text { of the } \\
\text { Ridge }\end{array}$} & B1 & 0.098 & 0.024 & L1 & 0.050 & 0.010 & M1 & 0.087 & 0.0057 \\
\hline & B2 & 0.092 & 0.0025 & L2 & 0.056 & 0.0043 & M2 & 0.088 & 0.010 \\
\hline & B3 & 0.311 & 0.0012 & L3 & 0.198 & 0.0046 & M3 & 0.090 & 0.011 \\
\hline \multirow{3}{*}{$\begin{array}{c}\text { Middle } \\
\text { of } \\
\text { Buccal } \\
\text { flange }\end{array}$} & B1 & 0.214 & 0.0041 & L1 & 0.148 & 0.0042 & M1 & 0.261 & 0.0028 \\
\hline & B2 & 0.078 & 0.011 & L2 & 0.036 & 0.0087 & M2 & 0.253 & 0.0046 \\
\hline & B3 & 0.279 & 0.0052 & L3 & 0.171 & 0.0028 & M3 & 0.258 & 0.0004 \\
\hline \multirow{3}{*}{$\begin{array}{l}\text { Middle Of } \\
\text { Lingual } \\
\text { flange }\end{array}$} & B1 & 0.177 & 0.0029 & L1 & 0.094 & 0.0057 & M1 & 0.182 & 0.0053 \\
\hline & B2 & 0.043 & 0.011 & L2 & 0.036 & 0.0072 & M2 & 0.186 & 0.011 \\
\hline & B3 & 0.246 & 0.0079 & L3 & 0.128 & 0.0077 & M3 & 0.185 & 0.0050 \\
\hline
\end{tabular}

B1 Balanced occlusion leveled with the upper third of Retro molar pad

B2 Balanced occlusion leveled with the middle third of Retro molar pad

B3 Balanced occlusion leveled with the lower third of Retro molar pad

L1 Lingualized occlusion leveled with the upper third of Retro molar pad

L2 Lingualized occlusion leveled with the middle third of Retro molar pad

L3 Lingualized occlusion leveled with the lower third of Retro molar pad

M1 Monoplane occlusion leveled with the upper third of Retro molar pad

M2 Monoplane occlusion leveled with the middle third of Retro molar pad

M3 Monoplane occlusion leveled with the lower third of Retro molar pad

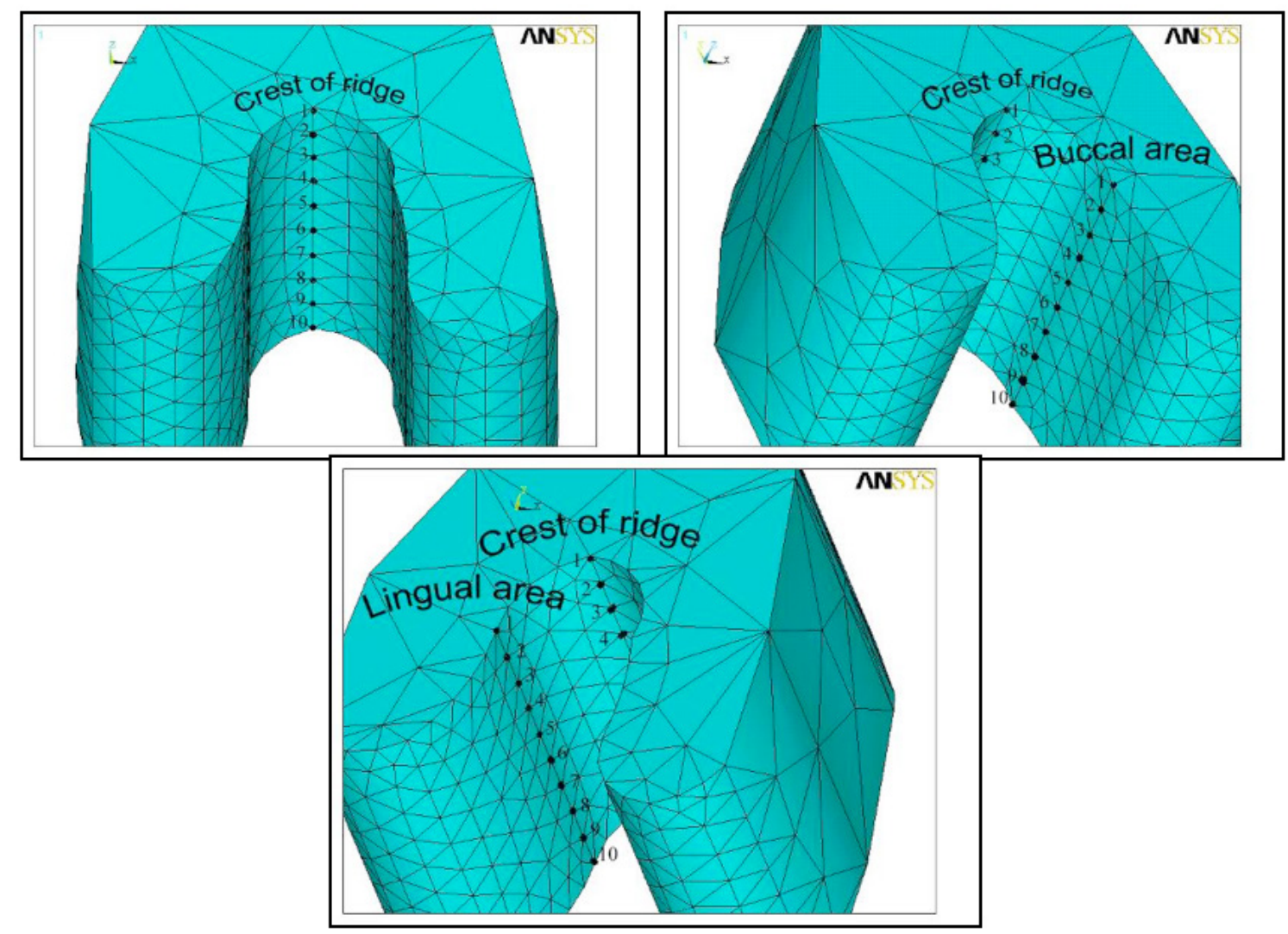

Fig. 1 Three dimensional model represent the site of nodes selected. 


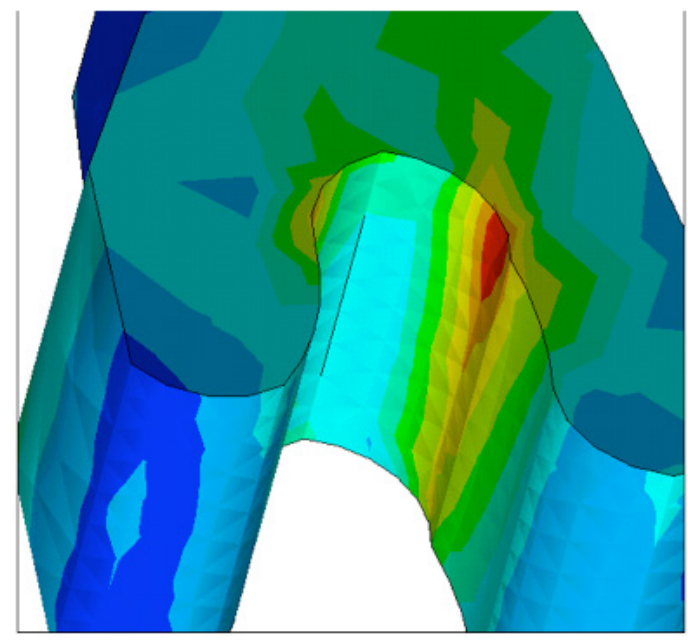

Crest of the ridge, buccal flange

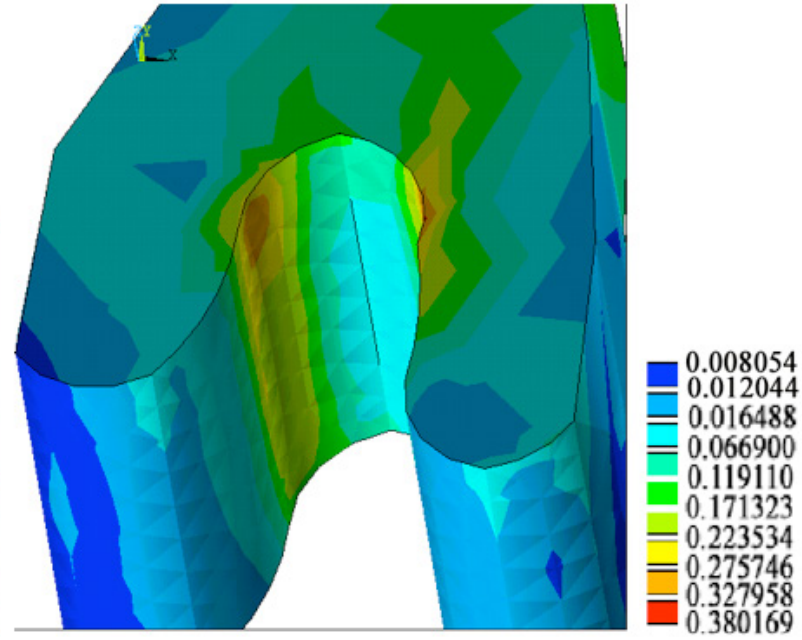

Crest of the ridge, lingual flange

Fig. 2 Balanced occlusion leveled with the upper third of retro molar pad

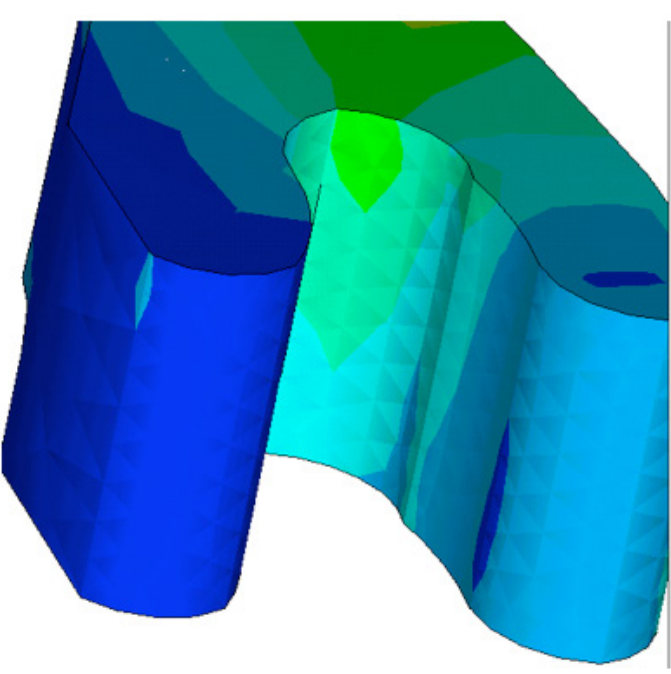

Crest of the ridge, buccal flange

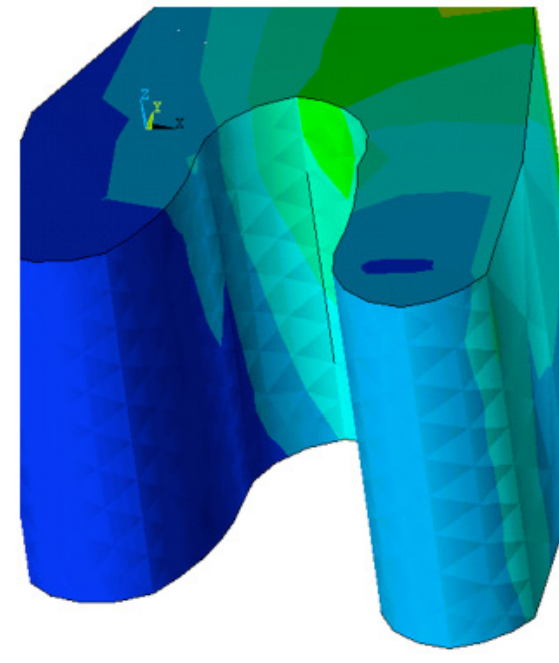

Crest of the ridge, lingual flange

Fig. 3. Balanced occlusion leveled with middle third of retro molar pad

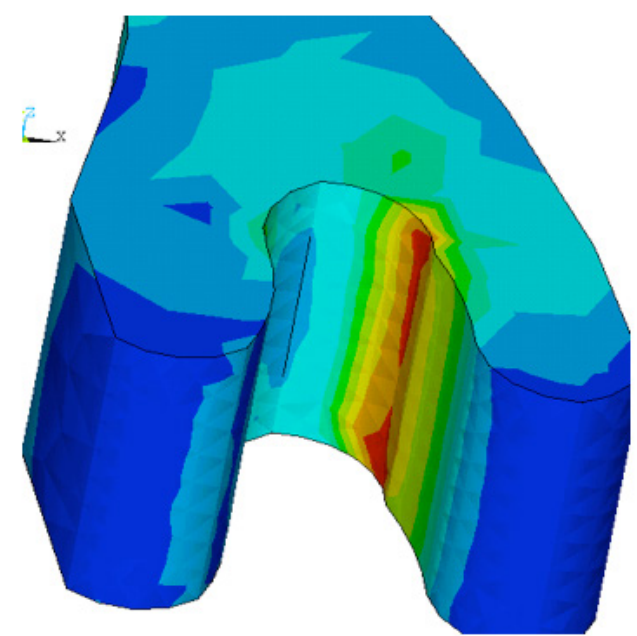

Crest of the ridge, buccal flange
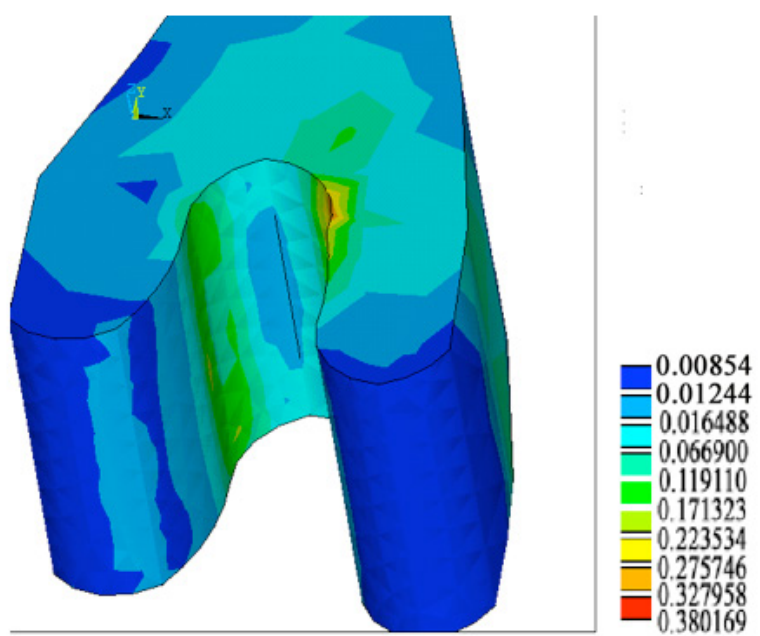

Crest of the ridge, lingual flange

Fig. 4.Monoplane occlusion 


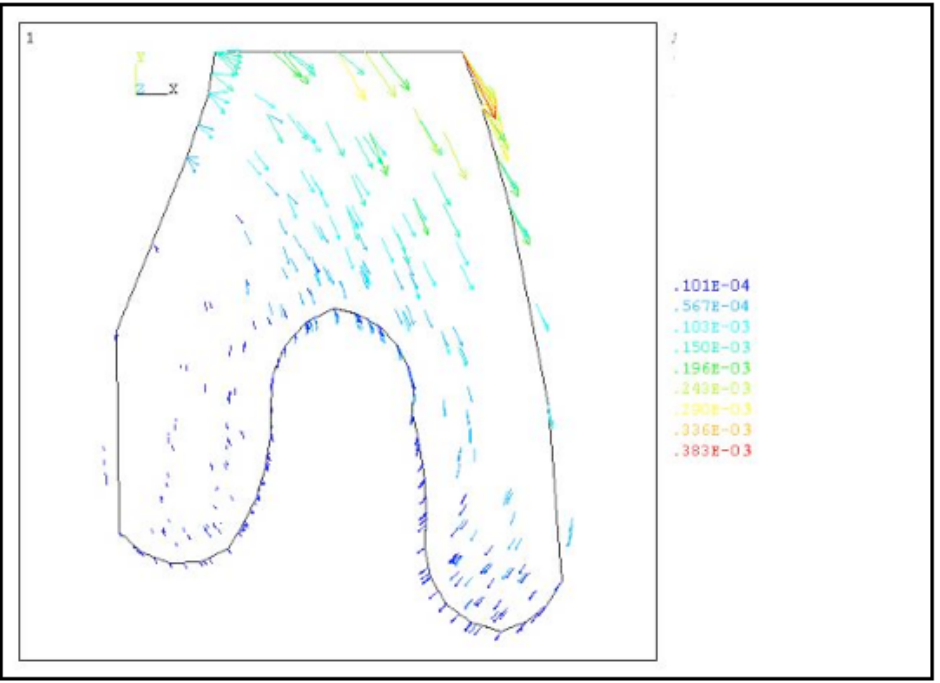

Fig. 5 Shows the displacement Vectors in balanced occlusion leveled with the middle third of RMP. $(\mathrm{mm})$

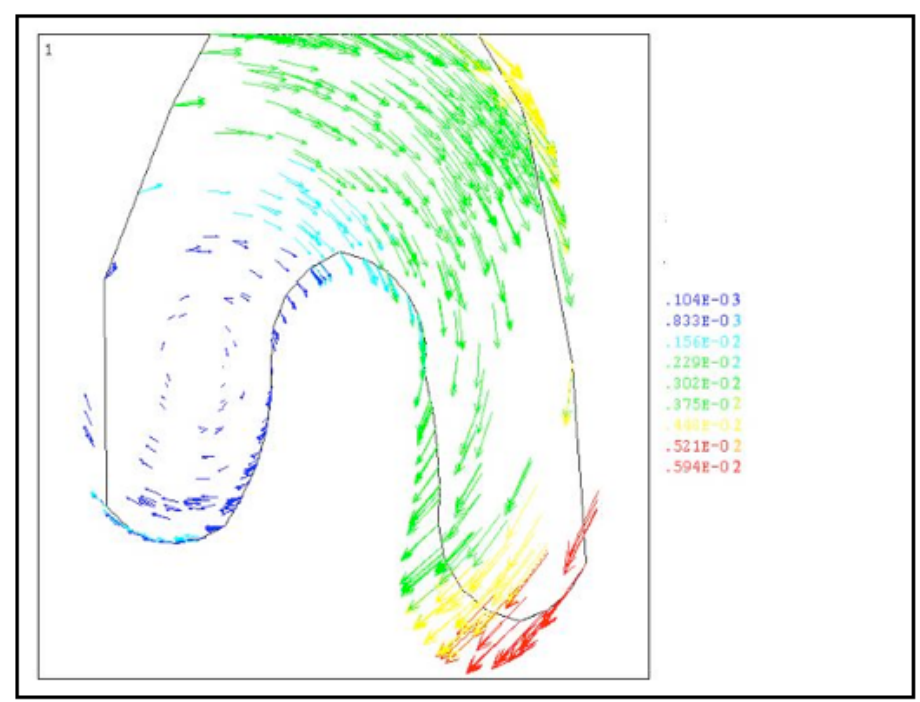

Fig.6: Shows the displacement Vectors in lingualized occlusion leveled with the lower third of RMP. ( $\mathrm{mm})$

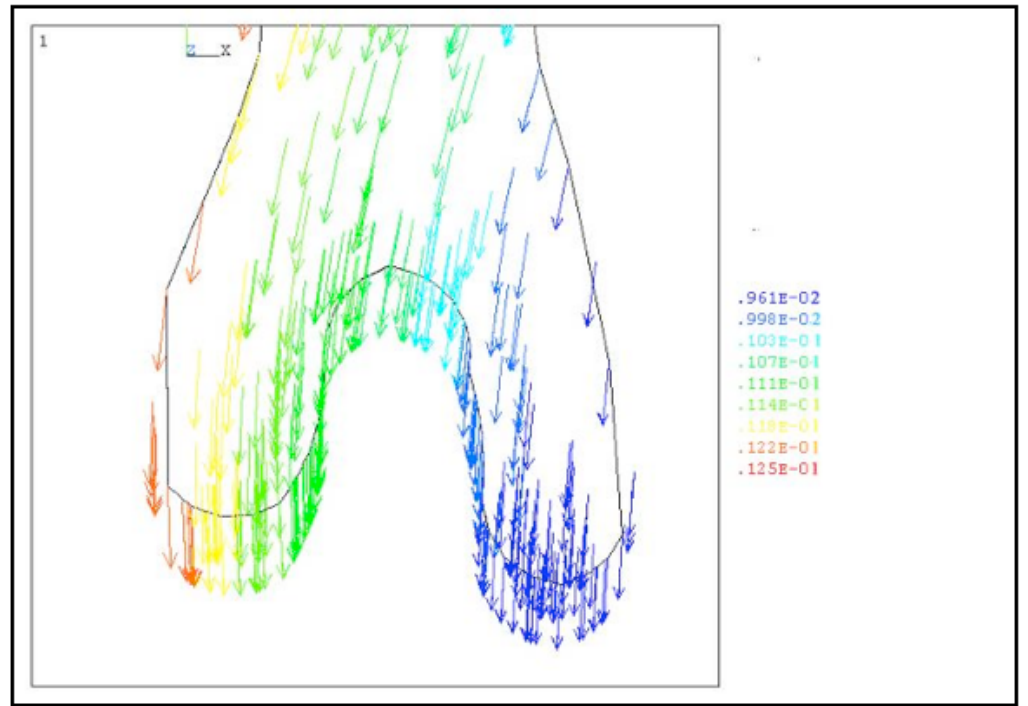

Fig..7 Shows the displacement Vectors in monoplane occlusion (mm)

\section{REFERENCES}

1. Boening K. and Waker M. Computer aided evaluation of occlusal load in complete denture. J. prosth. Dent. 1992, 67(3)339-44.

2. Kydd W. Complete denture base deformation with various occlusal teeth form. J. prosth. Dent 1956, 4(5):714-18.

3. Ismail YH. and Bowman JF. Position of the occlusal plane in natural and artificial teeth. J. prosth. Dent 1968, 20:407-10.

4. Jones PM.: The monoplane occlusion for complete denture JADA 1972, 85: 94-100.

5. Gromas DG. and Stout CJ. Linear occlusion concept for complete denture. J. prosth. Dent 1974, 32(2):122-129.

6. Inowe S.; Kawano F.; Nagao K. and Matsumoto N. Occlusal scheme and pressure distribution of supporting tissue. The international journal of prosth. 1996, 9 (2):179-87.

7. Ohguri T.; Kawano F.; Ichikawa T. and Matsumoto N. Occlusal scheme and pressure under complete denture. The international journal of prosth. 1999, 12(4):353-58.

8. Craig R. Restorative dental material.10th ed. Mosbey St. Louis 1997: 59-103.
9. Larrabee W. and Glat J. A finite element method of skin deformation .Laryngoscope 1986, 96:413-19.

10. Roedema WH. Occlusal table width and pressure under denture. J. prosth. Dent 1976, 36:24-34.

11. Kelsey CR.; Coplostz and Schoonmarker M. The effect of occlusal forms on pressure and bending during mastication with complete denture. J. prosth. Dent 1976, 55 (2):312.

12. Stromberg WR. A method of measuring forces of denture bases against supporting tissue J. prosth. Dent. 1954, 5(2):268-88.

13. Kydd W. Complete denture base deformation with various occlusal teeth form. J. prosth. Dent 1956, 4(5):714-18. 